\title{
Studies on the Chromosomes of Murine Dalton's Lymphoma Cells and the Effect of Cisplatin on Chromosomes of These Cells and Bone Marrow Cells in vivo
}

\author{
Surya B. Prasad ${ }^{1}$, Anirudha Giri and Dimos Khynriam \\ Cell and Tumor Biology Lab, Department of Zoology, School of Life Sciences, \\ North-Eastern Hill University, Shillong-793 022, India
}

Accepted August 21, 1998

\begin{abstract}
Summary Chromosome studies of Dalton's lymphoma (DL) revealed only one rb-marker in the cells and the chromosome numbers varied between 59 and 68 with a peak at 66 chromosomes. Thus, the modal number of chromosomes of this DL is suggested to be 66. Cisplatin treatment of tumor bearing hosts resulted the regression of the tumor and induced the formation of chromosomal aberrations/aberrant metaphases (80-90\%) in the DL cells which may be responsible for the anticancer activity of cisplatin. Cisplatin treatment of the hosts caused the significant decrease in GSH levels in DL as well as bone marrow cells. Cisplatin's mutagenic potentials in the host is also supported from the observation of the induction of chromosomal aberrations in the bone marrow cells of the same host. Differential effect of cisplatin on the chromosomes of bone marrow and Dalton's lymphoma cells is noted. Bone marrow cells developed significantly less aberrant metaphases as compared to that of DL cells after cisplatin treatment in vivo. Interestingly, aberrant metaphases in bone marrow cells decrease appreciably with time of treatment (48-96 hr) which may suggest the possibility of an efficient clearance/repair of Pt-DNA adducts in bone marrow cells but in DL cells it remained more or less constant.
\end{abstract}

Cis-Dichlorodiammineplatinum-II, commonly known as cisplatin, has become one of the most widely used chemotherapeutic agent (Pil and Lippard 1997) which has proved to be effective against a wide variety of experimental malignant tumors (Kociba et al. 1970, Sodhi and Aggarwal 1974, Prasad and Giri 1994) and also in the treatment of many human cancers (Carter 1984, Jurga et al. 1994). Many of the biological properties and effects of cisplatin have been well documented (Rosenberg 1985, Chu 1994). However, therapeutic efficacy of cisplatin has been limited due to the development of drug resistance (Dabholkar and Reed 1996) and dose-limiting side effects, mainly nephrotoxicity (Krakoff 1979). Furthermore, the mutagenic potency of cisplatin reported in bacteria (Cross et al. 1996) as well as mammalian system (Zwelling et al. 1979) raises the concern that its use in cancer chemotherapy may have carcinogenic risk with the development of secondary malignancies (Greene 1992). Many reports have been published describing the intercalation of cisplatin with DNA (Pascoe and Roberts 1974, Pinto and Lippard 1985, Zamble and Lippard 1995) which suggest that the cellular DNA could be the primary target for cisplatin in its cytotoxicity. It has been revealed that cisplatin functions as a bifunctional alkylating agent, producing DNA-interstrand crosslinks, DNA-protein crosslinks and DNA-intrastrand crosslinks (Zamble and Lippard 1995). However, in addition to its interaction with cellular DNA, the changes in various biochemical/enzymatic parameters, immune response, cell surface etc have also been observed which led to propose the involvement of multistep and multilevel effects of cisplatin in the tumor cell/host during cisplatin mediated chemotherapy against cancers (Giri 1995).

1 To whom correspondence should be addressed. 
Earlier we reported that the treatment of murine Dalton's lymphoma bearing mice with single therapeutic dose $(8 \mathrm{mg} / \mathrm{Kg}$ body wt, i.p.) of cisplatin leads to the regression of the tumor with various biochemical changes in ascites, appearance of membrane vesicles and infiltration of leukocytes towards tumor cells (Prasad and Giri 1994). Cisplatin has been reported to cause chromosomal aberrations and mutations in cultured mammalian cells (Van den Berg and Roberts 1975, Zwelling et al. 1979, Bocian et al. 1983).

The present studies were undertaken to investigate the differential in vivo effect of therapeutic dose of cisplatin on the chromosomes of Dalton's lymphoma (DL) cells and bone marrow cells of the tumorous hosts, so as to evaluate the development of mutagenic effects, if any, in the hosts during cisplatin chemotherapy. A chromosomal analysis of untreated control DL cells has also been made and discussed in view of earlier reports.

\section{Materials and methods}

Chemicals Cisplatin was a gift from Prof. C. L. Litterst of NIH, U.S.A. Colchicine and sodium citrate were purchased from 'SRL Co'., Mumbai. Giemsa's stain, ethylenediaminetetraacetic acid-disodium (EDTA) were from 'Glaxo', Mumbai. Reduced glutathione, 5,5'-dithio-bis-2-nitrobenzoic acid (DTNB) were bought from 'Sigma chemicals' U.S.A. Cisplatin was thoroughly mixed in $0.89 \% \mathrm{NaCl}$ in darkness $10-15 \mathrm{~min}$ before use. All other chemicals used were of analytical grade. Double distilled water was always used in the preparation of various solutions.

Tumor maintenance Ascites Dalton's lymphoma originally obtained from Gauhati University is being maintained in vivo in 10-12 weeks old inbred Swiss albino mice by serial intraperitoneal (i.p.) transplantations of $1 \times 10^{7}$ tumor cells per animal $(0.25 \mathrm{ml}$ vol. in phosphate buffered saline, PBS, $0.15 \mathrm{M} \mathrm{NaCl}, 0.01 \mathrm{M}$ sodium phosphate buffer, $\mathrm{pH}$ 7.4). Tumor transplanted animals survive for 22-24 days. Only the tumorous mice were used for the experiments.

Cisplatin treatment and chromosomal analysis Tumor transplanted animals were divided into two groups consisting of 10 mice each according to randomized block design. Average body weights were recorded daily for both the groups to indicate ascites tumor growth. One group of mice was administered with single therapeutic dose of cisplatin $(8 \mathrm{mg} / \mathrm{Kg}$ body wt) on the 10 th day post-tumor transplantation and the body weights were recorded daily and compared with that of control untreated group. As a significant regression in the tumor was noted with very little ascites recoverable from the treated hosts at 6-7 days of cisplatin treatment, the treatment schedule for 1 to 4 days only was used to observe its effect on the chromosomes.

Metaphase chromosomes from DL cells collected from untreated control mice were prepared on the 10th day of tumor transplantation. Mitotic arrest was initiated $1.5 \mathrm{hr}$ prior to sacrificing the control or cisplatin treated ( $8 \mathrm{mg} / \mathrm{Kg}$ body wt, i.p.) mice by injection of colchicine $(4 \mathrm{mg} / \mathrm{Kg}$ body wt, i.p.). Ascites fluid was collected and centrifuged (1000 rpm for $5 \mathrm{~min}$ ). Cells were washed once in Hanks' balanced salt solution and to the cell pellet $9-10 \mathrm{ml}$ of warm $\left(37^{\circ} \mathrm{C}\right) 1 \%$ sodium citrate was added and incubated for $15 \mathrm{~min}$. It was then centrifuged $(1000 \mathrm{rpm}, 10 \mathrm{~min})$ and the cell pellet was fixed in acetic acid: methanol $(1: 3, \mathrm{v} / \mathrm{v})$. Centrifugation and fixation were repeated twice with a 30 min interval. Finally the cells were suspended in small volume of fixative and flushed gently until a cloudy suspension resulted. Slides of these cells were prepared by the air-drying technique, stained with Giemsa ( $5 \mathrm{ml}$ of stock stain $+4 \mathrm{ml}$ methanol $+91 \mathrm{ml}$ phosphate buffer, $\mathrm{pH} 6.8$ ), washed and mounted in DPX. One hundred good metaphase spreads were examined per animal. 36 animals were used for control or each time interval of cisplatin treatment.

In the same way chromosome metaphase plates from bone marrow cells of the cisplatin treated and control tumorous animals were also prepared.

Glutathione (GSH) estimation Glutathione was measured as the total sulfhydryl (TSH) contents in the bone marrow and DL cells of untreated control tumor bearing mice or treated with cis- 
platin for $24 \mathrm{hr}$ using the methodology described by Sedlak and Lindsay (1968). Ascites tumor and bone marrow cell suspensions were centrifuged, cell pellets were collected and homogenized in $0.02 \mathrm{M}$ EDTA, $\mathrm{pH} 4.7$. To the homogenate or pure reduced GSH $(100 \mu \mathrm{l}), 0.02 \mathrm{M}$ EDTA $(0.9 \mathrm{ml})$, $0.2 \mathrm{M}$ Tris-EDTA buffer, pH $8.2(1.0 \mathrm{ml})$ and $20 \mu \mathrm{l}$ of Ellman's reagent $(10 \mathrm{mM}$ DTNB in absolute methanol) was added. It was mixed gently and after $30 \mathrm{~min}$ of incubation at room temperature the reaction solution was centrifuged and the absorbance of the supernatants were read at $412 \mathrm{~nm}$. The measurement was repeated four times independently in separate animals.

\section{Results}

Control tumor transplanted mice showed the regular increase in body weight indicating tumor growth upto 20-21 days and thereafter it declines slightly until the death of the animals. However, cisplatin treatment of the hosts caused a decrease in average body weight (Fig. 1), thus, showing an effective regression in tumor.

The chromosome complement of Dalton's lymphoma was determined from well spread metaphases. Chromosome number varied from 59 to 68 in different plates. However, majority of cells (more than 60\%) showed 66 chromosomes which is suggested as the modal number for this Dalton's lymphoma with one metacentric marker chromosome (Figs. 2, 3). However, metaphases with chromosome number 122-130 (nearly diploid) and 255-259 (highly heteroploid) were also observed occasionally. Control Dalton's lymphoma and bone marrow cells showed about $6 \%$ and $0.5 \%$ of aberrant metaphases respectively. However, cisplatin treatment for 24-96 hr drastically affected the DL cells resulting in a very high frequency (80-90\%) of aberrant metaphases (Fig. 4). Chromosomal aberrations included mainly chromatid breaks/gaps/exchanges, isochromatid gaps/breaks. However, chromatid and isochromatid breaks (together about 77\%) occurred more frequently. The chromosomal pulverization, as defined by Savage (1976) was observed in about $70 \%$ of treated DL cells. As compared to DL cells cisplatin treatment for $24 \mathrm{hr}$ resulted less aberrant metaphases in bone marrow cells (about 61\%) (Table 1). Comparative analysis of cisplatin treatment in DL and bone marrow cells for 24 to $96 \mathrm{hr}$ showed that percentage of abnormal metaphases in DL cells did not show much variation while in bone marrow cells it decreased appreciably (Fig. 4). Total chromosomal aberrations per cell for DL and bone marrow cells also showed similar trend and at corresponding time point the chromosomal aberrations in DL cells were always significantly higher than that in bone marrow cells (Table 1).

Glutathione determinations revealed that cisplatin treatment of the hosts resulted a significant decrease in GSH levels of DL as well as bone marrow cells (Fig. 5).

\section{Discussion}

The tumor, Dalton's lymphoma, was originated in the thymus gland of DBA/2 mouse at the National Cancer Institute, Bethesda, MD, USA in 1947 and subsequently, an ascites form was developed by repeated intraperitoneal (i.p.) transplantation of the tumor (Goldie and Felix 1951). In India probably this tumor cell line was first procured by Cancer Research Institute, Mumbai. The ascites tumor used in the present study was collected from Gauhati University in the year 1989. Chromosome complements of tumor cells are very often characterized by the presence of one or more marker chromosome(s) formed by Robertsonian translocations or tandem fusion (Rowley 1980). However, the exact significance of such markers and their relationship with the malignancy is not clearly defined. Chakrabarti et al. (1984) reported that modal chromosomal number in DL cells was 71 and there was only one rb-marker. However, after successive transplantations in vivo they reported the appearance of a new clone of cells which gradually predominated having two rbmarkers and the modal number reduced to 70 . From the present study, however, the chromosome 


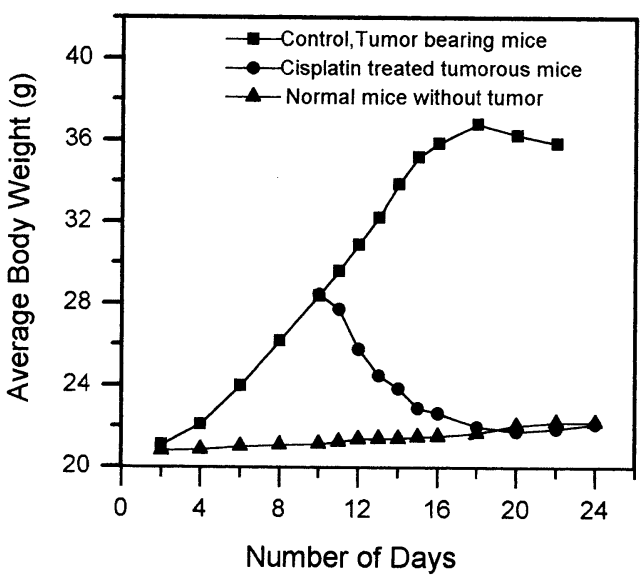

Fig. 1. Graph showing the comparative changes in the body weights of mice in different groups. A regular increase in body weights of untreated tumor transplanted mice shows the regular tumor growth while a decrease in the body weights of tumorous mice after cisplatin treatment indicates an effective retardation of tumor growth.

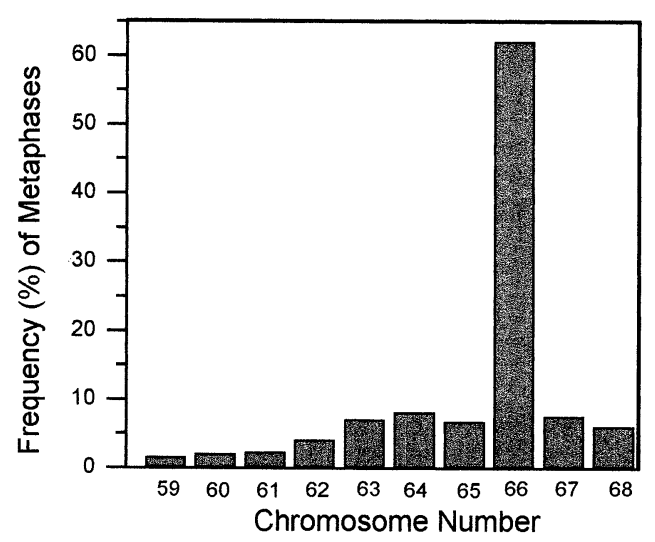

Fig. 3. Histogram showing the variation in chromosome number of ascites Dalton's lymphoma cells. A total of about 100 metaphases from four hosts were examined for this analysis.

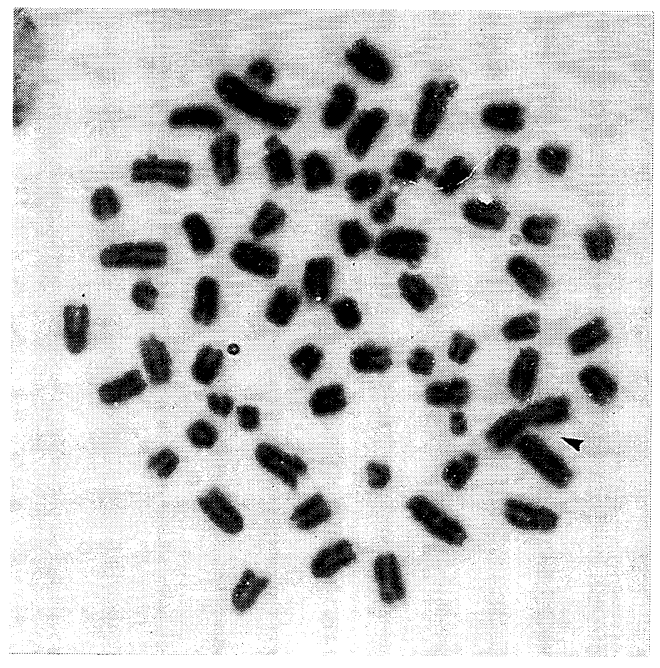

Fig. 2. Photomicrograph of a representative metaphase chromosome spread of murine ascites Dalton's lymphoma cells showing the modal number of chromosomes $=66$. Note the presence of characteristic one metacentric marker chromosome (arrowhead).

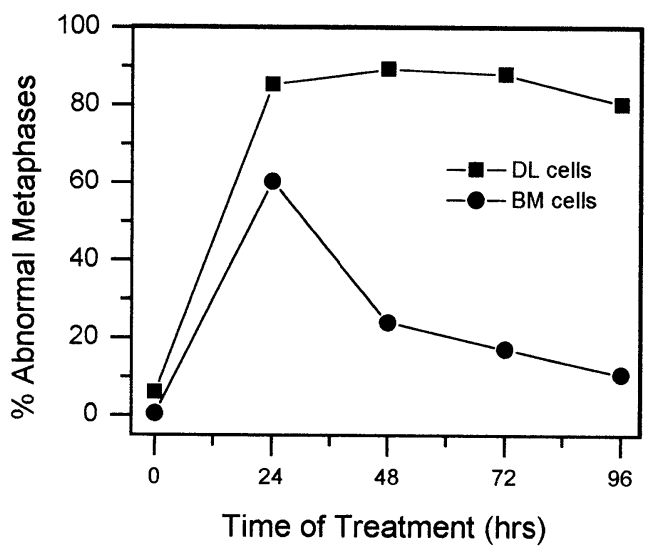

Fig. 4. Graph showing the percent changes in aberrant metaphase spreads in the population of Dalton's lymphoma (DL) and bone marrow (BM) cells treated with or without cisplatin in vivo.

model number in DL cells is suggested to be 66 with only one rb-marker (Fig. 2). This modal number is represented by more than $60 \%$ of DL cells (Fig. 3). It has been suggested that the differences in the chromosome complements/rb-marker might play a role in the growth rate, maintenance and adaptibility of the tumor strain in the heterologous host (Hamerton 1970). Even the cells adapted to growth in vitro often show karyotypic changes as compared with the karyotype of the in vivo parent cell line (Dowjat and Kawiak 1979). Therefore, the observed difference in the modal number in present study and that reported earlier by Chakrabarti et al. (1984) may be due to differential adaptability of DL cells in the hosts. The Dalton's lymphoma was adopted to Swiss albino mice in our laboratory while earlier it was being maintained in $\mathrm{C}_{3} \mathrm{H} / \mathrm{He}$ mice at Gauhati University.

Many studies on the reactions of cisplatin with nucleic acid component indicated that the cel- 


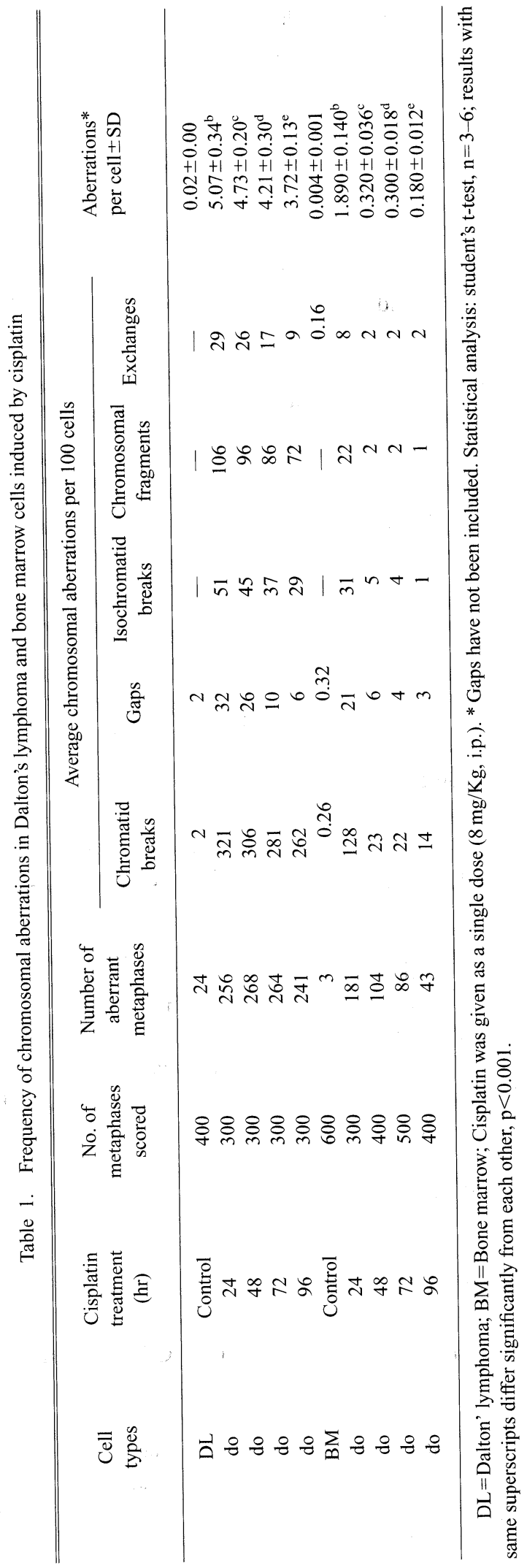


lular DNA could be the primary target in its anticancer activity (Sherman and Lippard 1987, Zamble and Lippard 1995). Platinum compounds reacted with the nitrogen atoms of nucleic acid bases guanine, adenine and cytosine (Pinto and Lippard 1985). Of the various possible binding modes it was suggested that those at the N-7 positions of adenine and guanine were the most likely sites to be involved in reactions with DNA (Zamble and Lippard 1995, Fichtinger-Schepman et al. 1995). Development of chromsomal aberrations in the cells have been commonly used as the mutagenic bioassays of a drug (Tandon and Sodhi 1985, Giri and Prasad 1996).

Here we report that the antitumor drug, cisplatin brings about differential effect on the chromosomes of DL and bone marrow cells of the same tumorous host. The cisplatin's effect on DL cells causing chromosomal aberrations remain higher than that of bone marrow cells and these could be the likely cause of cytotoxicity/cell death induced by cisplatin. This suggestion is supported by the fact that during cisplatin treatment for 24 to $96 \mathrm{hr}$ always above $80 \%$ aberrant metaphases were observed in DL cells (Fig. 4). Nevertheless, the mutagenic potentiality of cisplatin is also noted, causing chromosomal aberrations in the bone marrow cells of the same host (Table 1). However, the aberrant metaphases developed in bone marrow cells were comparatively quite less than that observed in DL cells after cisplatin treatment, and interestingly during later periods of cisplatin treatment $(48-96 \mathrm{hr})$ there is appreciable decrease in aberrations in bone marrow cells while in DL cells it always remained very high showing almost no change in the percent abnormal metaphases (Fig. 4). It indicates that bone marrow cells had gradual and effective recovery with only about $10 \%$ of the cells showing aberrations at $96 \mathrm{hr}$ of the cisplatin treatment (Fig. 4).

The exact mechanism of the cisplatin induced chromosomal aberrations and its differential effect in DL and bone marrow cells is not conclusively understood from the present studies. The glutathione (L- $\gamma$-glutamyl-L-cysteinyl glycine, GSH), a strong antioxidant, is the most prevalent intracellular thiol and is involved in various protective functions in the cell (Arrick and Nathan 1984). As the role of GSH in the metabolism of chemotherapeutic agents (Arrick and Nathan 1984), including cisplatin (Suzuki and Cherian 1990, Sugimoto et al. 1996) has been suggested, the GSH contents were measured in the bone marrow and DL cells of mice treated with or without cisplatin. It was observed that cisplatin treatment caused a significant decrease in cellular GSH (Fig. 5). Cisplatin mediated nephrotoxic effects has been reported to be developed by a decrease in the GSH level in kidney cortical slices in vitro (Nakano and Gemba 1989) and in vivo (Suzuki and Cherian 1990). A decrease in cellular GSH noted in present experiment after cisplatin treatment could be involved to develop less protective function in the cells and thereby developing higher mutagenic effects. Cisplatin has been reported to interact with cellular GSH (Eastman 1987, Corden 1987) and therefore may play a role in determining cellular sensitivity to cisplatin by preventing platination of critical loci in the cell. Under decreased cellular GSH levels, the amount of drug which may reach the critical DNA target in chromosomes would be more, thereby, developing higher chromosomal aberrations. Eastman (1991) reported that in an in vitro incubation a reduction of only $20 \%$ in the platination of DNA was observed at $1 \mathrm{mM} \mathrm{GSH}$ and a $70 \%$ reduction at $10 \mathrm{mM} \mathrm{GSH}$.

However, gradual decrease in the frequency of chromosome damage in bone marrow cells at 
later periods could be due to various possible reasons such as the clearance of drug from the body, post-replication repair process etc because of which many of the Pt-DNA adducts could be cleared. Infact a relation between the drug-sensitivity and poor cisplatin-DNA adducts repair has been established (Dijt et al. 1988, Zamble and Lippard 1995). It has been suggested that cisplatin lesions on guanine in DNA of normal cells could be repaired before replication, while in cancer cells because of a deficiency in this repair process, the lesions are not removed and the burden of mutations increases beyond the limits of survival (Rosenberg 1985). Rosenberg (1985) suggested that in cancer cells because of deficiency in the repair process, cisplatin lesions are not removed and it may lead to cell death. It has been suggested that different adducts could be responsible for the cytotoxicity and mutagenicity exerted by the drug, cisplatin. An adduct linking 2 guanines $\left[\operatorname{cis}\left[\operatorname{Pt}\left(\mathrm{NH}_{3}\right)_{2}\{\mathrm{~d}(\mathrm{GpG})-\right.\right.$ N7(1),-1N7(2) $\}$ ] has been associated with cytotoxicity, whereas an adduct which cross-links an adenine and a guanine $\left[\right.$ cis- $\left[\mathrm{Pt}\left(\mathrm{NH}_{3}\right)_{2}\{\mathrm{~d}(\mathrm{ApG})-\mathrm{N} 7(1),-\mathrm{N} 7(2)\}\right]$ is probably responsible for the mutagenicity (Bradley et al. 1993, Yarema et al. 1994). Pera et al. (1987) using different cell lines suggested that sensitivity to cisplatin may be a function of DNA repair or of cellular tolerance for PtDNA lesions.

Whatever could be the reason(s), results from the present studies clearly show the differential effect of cisplatin on the chromosomes of Dalton's lymphoma cells and bone marrow cells of the same host. It also supports the mutagenic potentiality of cisplatin in the hosts and that cytotoxicity of cisplatin could result from interaction with the cellular genetic material and it may have differential Pt-DNA interaction/repair in normal and cancer cells. However, further studies in this direction may strengthen these suggestions/findings.

\section{Acknowledgements}

The financial support was provided by North-Eastern Hill University. We are thankful to Dr. R. K. Bhola of Gauhati University for providing ascites Dalton's lymphoma, Dr. Samar Chakrabarti of Burdwan University for sending important related paper reprints and Mr. B. K. Das for technical assistance.

\section{References}

Arrick, B. A. and Nathan, C. F. 1984. Glutathione metabolism as a determinant of therapeutic efficacy: a review. Cancer Res. 44: 4224-4232.

Bocian, E. M., Laverick, M. and Nias, A. H. W. 1983. Sister chromatid exchanges induced by two radiosensizing platinum compounds cis-dichlorobis-isopropylamine-trans-dihydroxyplatinum (IV) (CHIP) and cis-platin metronidazole C/2 (FLAP) in CHO cells in vitro. Br. J. Cancer 48: 803-807.

Bradley, L. J. N., Yarema, K. J., Lippard, S. J. and Essigmann, J. M. 1993. Mutagenicity and genotoxicity of the major DNA adduct of the antitumor drug cis-diamminedichloroplatinum. Biochemistry 32: 982-988.

Carter, S. K. 1984. Cisplatin-past, present and future. In: Platinum Coordination Complexes in Cancer Chemotherapy (Eds. Hacker, M. P., Douple, E. B. and Krakoff, I. H.), Martinus Nijhpff Publishing, Boston, pp. 359-376.

Chakrabarti, S., Chakrabarti, A. and Pal, A. K. 1984. Chromosomal analysis of Dalton's lymphoma adapted to the Swiss mouse: clonal evaluation and C-heterochromatin distribution. Cancer Genet. Cytogenet. 11: 417-423.

Chu, G. 1994. Cellular responses to cisplatin. J. Biol. Chem. 269: 787-790.

Corden, B. J. 1987. Reaction of platinum (II) antitumor agents with sulfhydral compounds and the implications for nephrotoxicity. Inorg. Chim. Acta 137: 125-130.

Cross, H. J., Tilby, M., Chipman, J. K., Ferry, D. R. and Gescher, A. 1996. Effect of quercetin on the genotoxic potential of cisplatin. Int. J. Cancer 66: 404-408.

Dabholkar, M. and Reed, E. 1996. Cisplatin. In: Pinedo, H. M., Longo, D. L. and Chabner, B. A. (eds.), Cancer Chemotherapy and Biological Response Modifiers Annual 16, Elsevier Science Publishers, Netherlands, pp. 88-110.

Dijt, F. J., Fichtinger-Schepman, A. M. J., Berends, F. and Reedijk, J. 1988. Formation and repair of cisplatin-induced adducts to DNA in cultured normal and repair-deficient human fibroblasts. Cancer Res. 48: 6058-6062.

Dowjat, K. and Kawiak, J. 1979. Karyotype analysis of two L1210 murine leukemia lines growing in in vivo and in vitro. 
Cytologia 44: 927-934.

Eastman, A. 1987. Cross-linking of glutathione to DNA by cancer chemotherapeutic platinum coordination complexes. Chem. Biol. Interact. 61: 241-248.

- 1991. Mechanisms of resistance to cisplatin. In: Ozols, R. F. (ed.) Molecular and Clinical Advances in Anticancer Drug Resistance. Academic Publications, Boston. pp. 233-249.

Fichtinger-Schepman, A. M. J., Van Dijk-Knijnenburg, H. C. M., Van der Velde-visser, S. D., Berends, F. and Raan, R. A. 1995. Cisplatin- and carboplatin-DNA adducts: is Pt-AG the cytotoxic lesion? Carcinogenesis 16: 2447-2453.

Giri, A. 1995. Studies on the effect of cisplatin on malignant and normal cells: preliminary investigations on cisplatin combination chemotherapy. Ph.D. Thesis, North-Eastern Hill University, Shillong. pp. 1-268.

— and Prasad, S. B. 1996. Protective effect of vitamin C on cisplatin induced mutagenicity. In: Collery, P., Corbella, J., Domingo, J. L., Etienne, J. C. and Llobet, J. M. (eds.) Metal Ions in Biology and Medicine. John Libbey Eurotext, Paris, Vol. 4, pp. 306-308.

Goldie, H. and Felix, M. D. 1951. Growth characteristics of free tumor cells transformed serially in the peritoneal fluid of the mouse. Cancer Res. 11: 73-80.

Greene, M. H. 1992. Is cisplatin a human carcinogen? J. Natl. Cancer Inst. 84: 306-312.

Hamerton, J. L. 1970. Robertsonian translocation. In: Jacobs, P. A., Price, W. H. and Law, P. (eds.) Human Population Cytogenetics. Baltimore, pp. 63-80.

Jurga, L., Misurova, E., Kovac, V. and Sevcikova, I. 1994. The role of cisplatin in chemotherapy of advanced breast cancer. Neoplasma 41: 347-352.

Kociba, R. J., Sleight, S. D. and Rosenberg, B. 1970. Inhibition of Dunning ascitic leukemia and Walker-256 carcinosarcoma with cis-diamminedichloroplatinum (NSC-119875). Cancer Chemother. Rep. 54: 325-328.

Krakoff, I. H. 1979. Nephrotoxicity of cis-dichlorodiammineplatinum. Cancer Treat. Rep. 63: 1523-1525.

Nakano, S. and Gemba, M. 1989. Potentiation of cisplatin-induced lipid peroxidation in kidney cortical slices by glutathione depletion. Japan. J. Pharmacol. 50: 87-92.

Pascoe, J. M. and Roberts, J. J. 1974. Interactions between mammalian cell DNA and inorganic platinum compounds. Biochem. Pharmacol. 23: 1345-1357.

Pera, M. F., Friedlos, F., Mills, J. and Roberts, J. J. 1987. Inherent sensitivity of cultured human embryonal carcinoma cells to adducts of cis-diamminedichloroplatinum (II). Cancer Res. 47: 6810-6813.

Pil, P. and Lippard, S. J. 1997. Cisplatin and related drugs. In: Bertino, J. R. (ed.) Encyclopedia of Cancer. Academic Press, Inc. San Diego, Vol. 1, pp. 392-410.

Pinto, A. L. and Lippard, S. J. 1985. Binding of the antitumor drug cis-diamminedichloroplatinum (II) (cisplatin) to DNA. Biochim. et Biophys. Acta 780: 167-180.

Prasad, S. B. and Giri, A. 1994. Antitumor effect of cisplatin against murine ascites Dalton's lymphoma. Ind. J. Exp. Biol. 32: $155-162$.

Rosenberg, B. 1985. Fundamental studies with cisplatin. Cancer 55: 2303-2316.

Rowley, J. D. 1980. Chromosome abnormalities in cancer. Cancer Genet. Cytogenet. 2: 175-198.

Savage, J. P. K. 1976. Classification and relationships of induced chromosomal structural changes. J. Med. Gen. 13: 103122.

Sedlak, J. and Lindsay, R. H. 1968. Estimation of total, protein-bound, and nonprotein sulfhydryl groups in tissues with Ellman's reagent. Anal. Biochem. 25: 192-205.

Sherman, S. E. and Lippard, S. J. 1987. Structural aspects of platinum anticancer drug interaction with DNA. Chem. Rev. 87: 1153-1181.

Sodhi, A. and Aggarwal, S. K. 1974. Effects of cis-dichlorodiammine platinum (II) in the regression of Sarcoma-180: a fine structural study. J. Natl. Cancer Inst. 53: 85-101.

Sugimoto, C., Matsukawa, S., Fujieda, S., Noda, I., Tanaka, N., Tsuzuki, H. and Saito, H. 1996. Involvement of intracellular glutathione in induction of apoptosis by cisplatin in a human pharyngeal carcinoma cell line. Anticancer Res. 16: $675-680$.

Suzuki, C. A. M. and Cherian, M. G. 1990. The interactions of cis-diamminedichloroplatinum with metallothionein and glutathione in rat liver and kidney. Toxicology 64: 113-127.

Tandon, P. and Sodhi, A. 1985. Cis-dichlorodiammine platinum (II) induced aberrations in mouse bone-marrow chromosomes. Mutat. Res. 156: 187-193.

Van den Berg, H. W. and Roberts, J. J. 1975. Post-replication repair of DNA in Chinese hamster cells treated with cis-platinum (II) diamminedichloride: Enhancement of toxicity and chromosome damage by caffeine. Mutat. Res. 33: 279-284.

Yarema, K. J., Wilson, J. M., Lippard, S. J. and Essigmann, J. M. 1994. Effects of DNA adduct structure and distribution on the mutagenicity and genotoxicity of two platinum anticancer drugs. J. Med. Chem. 236: 1034-1048.

Zamble, B. D. and Lippard, S. J. 1995. Cisplatin and DNA repair in cancer chemotherapy. Trends in Biochem. Sci. 20: 435-439. 
Zwelling, L. A., Bradley, M. O., Sharkey, N. A., Anderson, T. and Kohn, K. W. 1979. Mutagenicity, cytotoxicity and DNA crosslinking in V79 Chinese hamster cells treated with cis- and trans-Pt(II) diamminedichloride. Mutat. Res. 67: $271-280$. 